\title{
OPTIMALISASI BIAYA PELAKSANAAN KONSTRUKSI JALAN DENGAN METODE LOGIKA FUZZY FIS TAKAGI-SUGENO PADA PROYEK JALAN TRANS KALIMANTAN PROVINSI KALIMANTAN UTARA
}

\author{
Febryan Nugraha $^{1 *}$, Alwafi Pujiraharjo ${ }^{2}$ dan Ruslin Anwar ${ }^{2}$ \\ ${ }^{1}$ Mahasiswa / Program Magister Teknik Sipil / Universitas Brawijaya \\ ${ }^{2}$ Dosen / Jurusan Teknik Sipil / Universitas Brawijaya \\ Korespondensi : febryan.nugraha16@gmail.com
}

\begin{abstract}
National development requires infrastructure as one of the driving wheel of economic growth. One of the main parts of infrastructure development is the construction of highways. Road construction requires many factors to consider before the development process begins, such as factors of materials, equipment, labor, time and cost. In practice, accurate calculations are needed in determining the required amount of each factor, since a slight mistake can cause losses on the part of the contractor that impact the low quality of the highway. In this research used fuzzy logic (fuzzy logic) as decision maker. Because the workings of fuzzy logic represent the way of human thinking that appears from the outside and contained in the form of words. Fuzzy logic is a logic that has the value of vagueness or fuzzyness between right and wrong. In fuzzy logic theory a value can be true or false at the same time. Fuzzy itself in the language is interpreted as or vague.Fuzzy logic has degrees of membership in the vulnerable 0 to 1 . Fuzzy logic used as a pointer to the extent to which the value is true and the extent to which the value is wrong, in contrast to classical logic, a value has only two the possibility of being a member of the set or not. Fuzzy logic can also be used as an alternative decision-making as an easy modern control system. The fuzzy logic used is FIS Takagi-Sugeno because of its more efficient computing, works well for linear techniques, works well for adaptive optimization and ensures continuity of results. In this research will also be developed an application that aims to assist users in analyzing and forecasting the needs of what is required in making a highway construction. Using the Takagi_Sugeno FIS based FIS user interface generated in this research, the resulting performance using Fuzzy Logic is better than the manual calculation, it can be seen from the total cost generated from the calculation method. For calculations using Fuzzy Logic has a total cost of Rp.52.950.009.851 while the results of manual calculations of Rp. 54.840.926.051.
\end{abstract}

Keyword: Fuzzy Logic, optimization, User Interface, Highways

\section{PENDAHULUAN}

Dalam perkembangan pembangunan nasional tidak dapat di pungkiri bahwa infrastruktur merupakan salah satu roda penggerak pertumbuhan ekonomi, bagian utama dari pembangunan infrastruktur adalah pembangunan jalan raya. Dimana jalan raya merupakan penghubung utama dalam suatu wilayah.

Dalam pembangunan jalan raya terdapat beberapa faktor yang perlu diperhatikan, karena pada prakteknya dibutuhkan perhitungan yang akurat dalam menentukan masing - masing faktor tersebut dan dalam pembangunan jalan raya perlu tahapan agar pembangunan berjalan dengan lancar salah satunya adalah tahapan estimasi.

AI (Artifikal Intelligence) sering digunakan sebagai sistem kendali yang cerdas dalam pengambilan keputusan serta mengoptimasi suatu sistem. Jadi AI sering digunakan dalam suatu proyek kontruksi karena dianggap dapat menghemat waktu dan dapat mengeluarkan hasil yang lebih optimal. [1] 
Pada penelitian ini, peneliti memilih logika fuzzy sebagai pengambilan keputusan dalam estimasi biaya pelaksanaan kontruksi jalan raya.

Berikut ini terdapat beberapa rumusan permasalahan dalam penenilitian ini, antara lain sebagai berikut :

1. Bagaimana optimasi perkiraan biaya pekerjaan jalan dengan metode logika Fuzzy Interface System Takagi Sugeno.

2. Bagaimana perkiraan biaya dengan metode logika Fuzzy Interface System Takagi Sugeno dengan realisasi pekerjaan yang telah dilaksanakan.

3. Berapa efisiensi perkiraan biaya pekerjaan dengan metode logika Fuzzy Interface System Takagi Sugeno.

\section{METODE PENELITIAN}

Penelitian ini dilakukan pada obyek penelitian proyek pembangunan jalan Trans Kalimantan Provinsi Kalimantan Utara.

\subsection{Data Penelitian}

Data yang dipergunkan dalam penelitian ini adalah data sekunder yang di ambil dari Dinas Pekerjaan Umun Daerah Kalimantan Utara. Data penelitian ini berupa data Kontruksi Pembangunan Jalan Raya.

\subsection{Variabel Penelitian}

Dalam Penelitian ini terdapat 4 variabel yaitu :

1. Variabel Cost/Biaya

2. Variabel Material/Bahan

3. Jumlah SDM

4. Manajemen Resiko

\subsection{Metode Pengumpulan Data}

Metode yang digunakan dalam penelitian ini adalah sebagai berikut :

1. Penentuan bahan dan alat

2. Spesifikasi Sistem

3. Perancangan Sistem

4. Langkah Penelitian

5. Perancangan Software System

6. Pengujian Sistem

7. Pengambilan Keputusan

8. Jadwal dan Pelaksanaan

\subsection{Kerangka Konsep Berfikir}

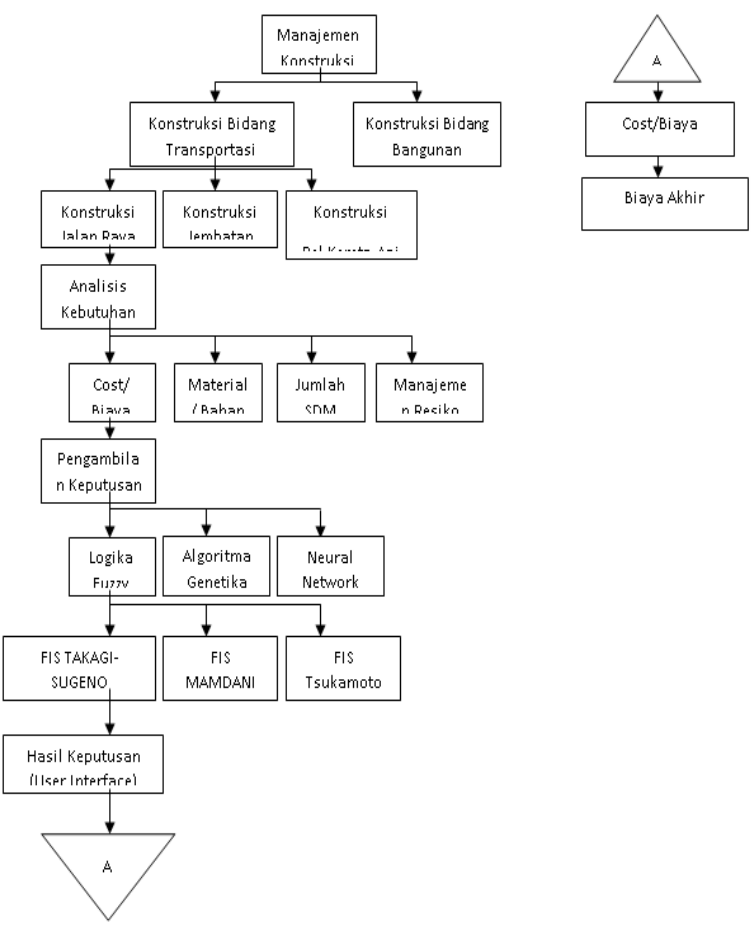

Gambar 1. Kerangka konsep berfikir

3. HASIL DAN PEMBAHASAN

3.1 Logika Fuzzy Interface System TakagiSugeno

Metode yang digunakan adalah logika fuzzy. Tahapan-tahapan dalam Logika Fuzzy ditunjukkan dalam diagram alir dibawah ini beserta penjelasannya. [2]

1. Menentukan variabel masukan dan variabel keluaran.

Dalam penelitian ini variabel masukan bagi logika fuzzy adalah berupa data Rencana Anggaran Biaya (RAB) dari proses pembangaunan jalan raya di Provinsi Kalimantan Utara.Variabel keluarannya adalah berupa konstanta atau suatu persamaan linear tergantung terhadap masukan dan keluaran sistem.

2. Menentukan jenis fungsi keanggotaan masukan dan keluaran serta pembagian nilai label atas beberapa variabel linguistik. Penentuan fungsi keanggotaan ini didasarkan pada hasil data yang diperoleh dengan menentukan batasan antara nilai rendah, sedang, dan tinggi dari tiga jenis data RAB. 
3. Pembentukan Aturan Fuzzy

Dalam sistem ini terdapat 21 input (item pekerjaan) yang dibutuhkan dalam pembangunan jalan raya, sehingga didapat 1 hingga 3 keadaan. Jadi, jumlah rule base dapat ditentukan berdasarkan kombinasi anggota himpunan fuzzy pada masing-masing himpunan fuzzy. Sedangkan untuk metode inferensi fuzzyatau fuzzifikasi yang digunakan adalah metode Takagi Sugeno dimana anteseden direpresentasikan dalam proposisi dalam himpunan fuzzy, sedangkan konsekuen direpresentasikan dengan sebuah konstanta atau persamaan linear.

4. Fuzzifikasi

Proses fuzzifikasi adalah proses mengubah variabel non fuzzy (variabel numerik) menjadi variabel fuzzy (variabel linguistik). Nilai masukan-masukan yang masih dalam bentuk variabel numerik yang telah dikuantisasi sebelum diolah oleh logika fuzzy harus diubah terlebih dahulu ke dalam variabel fuzzy. Melalui fungsi keanggotaan yang telah disusun maka dari nilai-nilai masukan tersebut menjadi informasi fuzzy yang berguna untuk proses pengolahan secara fuzzy. Pada proses ini penulis memberikan satu rangkaian perhitungan yang mewakili dari tiap hitungan setiap divisi dalam proses Fuzzifikasi.

\subsection{Divisi Drainase}

Pada grafik galian selokan drainase dan saluran air dibawah, garis merah menurun merupakan gambaran untuk volume pekerjaan dengan range rendah, garis biru adalah gambaran untuk volume pekerjaan dengan range menengah, sedangkan garis merah menaik adalah gambaran untuk volume pekerjaan dengan range tinggi. [3]

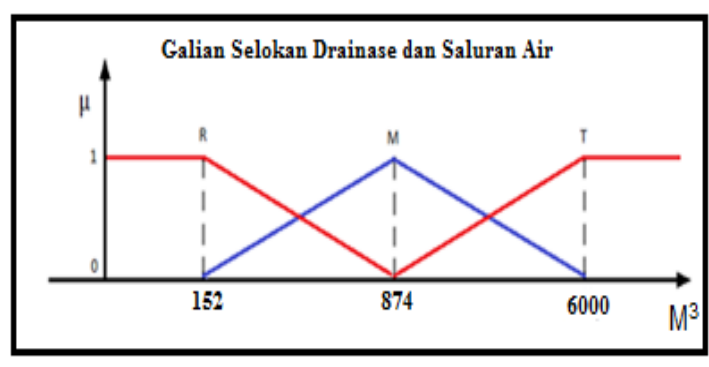

Gambar 2. Grafik selokan drainase dan saluran air
Untuk Range Rendah (R):

$\mu[x]=\left\{\begin{aligned} 1, & x \leq 152 \\ 0, & x \geq 874 \\ \frac{874-x}{874-152}, & 152<x<874\end{aligned}\right.$

Nilai yang digunakan pada range rendah untuk membership function adalah volume pekerjaan dengan range antara 152 sampai dengan 874 dalam satuan $\mathrm{m}^{3}$. Nilai $152 \mathrm{~m}^{3}$ adalah nilai batas minimum toleransi jumlah galian yang dapat digunakan dalam pekerjaan galian selokan.

\section{Untuk Range Menengah (M):}

$\mu[x]=\left\{\begin{array}{cl}0, \quad x \leq 152 \text { \&atau } x \geq 6000 \\ \frac{x-152}{874-152}, \quad 152<x \leq 874 \\ \frac{6000-x}{6000-874}, \quad 874<x<6000\end{array}\right.$

Nilai yang digunakan pada range menengah untuk membership function adalah volume pekerjaan dengan range antara 152 sampai dengan 6000 serta nilai optimasi pada 874 dalam satuan $\mathrm{m}^{3}$.

Untuk Range Tinggi (T):

$$
\mu[x]=\left\{\begin{array}{cc}
1, & x \geq 6000 \\
0, & x \leq 874 \\
\frac{x-874}{6000-874}, & 874<x<6000
\end{array}\right.
$$

\subsection{Rule Base System}

Pada hasil Rule Base System Untuk Divisi Drainase, data yang tertera di bawah merupakan hasil dari variable $\mathrm{Z}$ berdasarkan volume galian drainase yang divariasikan antara volume galian selokan drainase dan saluran air dengan volume pasangan batu mortar mulai dari range terendah hingga range tertinggi yaitu untuk range terendah $152 \mathrm{~m}^{3}$ sampai dengan $874 \mathrm{~m}^{3}$, range menengah dari $152 \mathrm{~m}^{3}$ sampai dengan $6000 \mathrm{~m}^{3}$, dan range tertinggi yaitu dari $874 \mathrm{~m}^{3}$ sampai dengan 6000 $\mathrm{m}^{3}$ untuk galian selokan drainase dan saluran air. Range terendah dari $112 \mathrm{~m}^{3}$ sampai dengan 644 $\mathrm{m}^{3}$, range menengah $112 \mathrm{~m}^{3}$ sampai dengan 1800 $\mathrm{m}^{3}$, range tertinggi dari $644 \mathrm{~m}^{3}$ sampai dengan $1800 \mathrm{~m}^{3}$ untuk volume pasangan batu mortar. 
1. IF galian selokan drainase dan saluran air (R) dan pasangan batu mortar (R) maka $\mathrm{Z}=154.121 .640$

2. IF galian selokan drainase dan saluran air (R) dan pasangan batu mortar (M) maka $Z=819.807 .920$

3. IF galian selokan drainase dan saluran air (R) dan pasangan batu mortar (T) maka $Z=2.266 .299 .160$

4. IF galian selokan drainase dan saluran air (M) dan pasangan batu mortar (R) maka $Z=220.513 .150$

\section{Defuzzifikasi}

Defuzzifikasi yaitu proses untuk mengubah fuzzy output menjadi crisp output (output dalam bentuk tegas menggunakan fungsi keanggotaan sebelumnya menjadi sebuah nilai).

$$
\mathrm{Z}=\frac{\mu_{1} \mathrm{Z}_{1}+\ldots+\mu_{n} \mathrm{Z}_{\mathrm{n}}}{\mu_{1}+\ldots+\mu_{\mathrm{n}}}
$$

Dimana :

$\mu_{1}=$ alpa predikat untuk rule pertama

$\mu_{n}=$ alpa predikat untuk rule ke-n sesuai jumlah rule pada masing-masing divisi

$\mathrm{Z}_{\mathrm{n}}=$ output bernilai $\mathrm{Z}$ untuk masing-masing rule $\mathrm{Z}=$ Nilai akhir yang diinginkan untuk analisis $\mathrm{RAB}$

Untuk nilai akhir merupakan penjumlahan dari nilai $\mathrm{Z}$ pada masing-masing divisi, total nilai $\mathrm{Z}$ merupakan jumlah biaya total hasil pekerjaan keseluruhan divisi.

- Divisi Drainase

- Galian selokan drainase dan saluran air $=6000 \mathrm{M}^{3}$

○ Pasangan Batu dengan Mortar $=1800$ $\mathrm{M}^{3}$

$\mu\left[\right.$ Galian selokan drainase dan saluran air $\left.=6000 \mathrm{M}^{3}\right]\left\{\begin{array}{l}\mu_{\mathrm{R}}=0 \\ \mu_{\mathrm{M}}=0 \\ \mu_{\mathrm{T}}=1\end{array}\right.$

$\mu\left[\right.$ Pasangan batu mortar $\left.=1800 \mathrm{M}^{3}\right]\left\{\begin{array}{l}\mu_{\mathrm{R}}=0 \\ \mu_{\mathrm{M}}=0 \\ \mu_{\mathrm{T}}=1\end{array}\right.$

$$
\begin{aligned}
Z= & \frac{\alpha_{\text {predikat }{ }_{9}} \times Z_{9}}{\alpha_{\text {predikat } 9}} \\
& =\frac{1 \times 2.804 .052 .000}{1} \\
& =2.804 .052 .000
\end{aligned}
$$

Tabel 1. Rule base divisi drainase

\begin{tabular}{|r|c|c|c|}
\hline Rule & $\begin{array}{c}\text { Galian selokan } \\
\text { drainase dan } \\
\text { saluran air }\end{array}$ & $\begin{array}{c}\text { Pasangan batu } \\
\text { mortar }\end{array}$ & $\boldsymbol{a}_{\text {predilkt }}$ \\
\hline 1 & 0 & 0 & 0 \\
\hline 2 & 0 & 0 & 0 \\
\hline 3 & 0 & 1 & 0 \\
\hline 4 & 0 & 0 & 0 \\
\hline 5 & 0 & 0 & 0 \\
\hline 6 & 0 & 1 & 0 \\
\hline 7 & 1 & 0 & 0 \\
\hline 8 & 1 & 0 & 0 \\
\hline 9 & 1 & 1 & 1 \\
\hline
\end{tabular}

Tabel 2. Hasil perhitungan

\begin{tabular}{|l|l|c|}
\hline No & \multicolumn{1}{|c|}{ Divisi } & $\begin{array}{c}\text { Total RAB (Rupiah) } \\
\text { Fuzzy Takagi Sugeno }\end{array}$ \\
\hline 1 & Divisi Umum & 311.450 .000 \\
\hline 2 & Divisi Drainase & 2.804 .052 .000 \\
\hline 3 & $\begin{array}{l}\text { Divisi Pekerjaan } \\
\text { Tanah }\end{array}$ & $23.295 .982,400$ \\
\hline 4 & $\begin{array}{l}\text { Divisi Pelebaran } \\
\text { perkerasan dan bahu } \\
\text { jalan }\end{array}$ & 1.500 .957 .900 \\
\hline 5 & $\begin{array}{l}\text { Divisi Perkerasan } \\
\text { berbutir dan } \\
\text { perkerasan beton } \\
\text { semen }\end{array}$ & 6.568 .976 .880 \\
\hline 6 & $\begin{array}{l}\text { Divisi perkerasan } \\
\text { aspal }\end{array}$ & 17.048 .736 .911 \\
\hline 7 & Divisi struktur & 1.414 .490 .760 \\
\hline 8 & $\begin{array}{l}\text { Divisi Pengembalian } \\
\text { kondisi dan } \\
\text { pekerjaan minor }\end{array}$ & 1.896 .279 .200 \\
\hline TOTAL & 52.950 .009 .851 \\
\hline
\end{tabular}




\section{KESIMPULAN}

Berdasarkan tahapan - tahapan analisis dan pengolahan data, diperoleh kesimpulan :

1. Hasil perhitungan rencana anggaran biaya yang dilakukan dengan menggunakan program Fuzzy menghasilkan nilai volume yang lebih efektif dengan menyeimbangkan volume di tiap item pekerjaan sehingga output volume dari aplikasi Fuzzy memiliki nilai volume yang pas untuk digunakan.

2. Kinerja yang dihasilkan metode Logika Fuzzy lebih baik dibandingkan dengan perhitungan manual, hal ini terlihat dari total biaya Rp. 54.840.926.051 yang didapatkan dari hasil perhitungan manual dapat dihemat menjadi Rp.52.950.009.851 apabila menggunakan program Fuzzy.

3. Dengan metode ini efisiensi perkiraan biaya menjadi lebih murah, dan mengalami perbaikan pada pengeluaran yang menjadi lebih hemat.

\section{SARAN}

Berdasarkan kesimpulan, saran yang dapat diberikan dalam tesis ini antara lain:

1. Metode yang digunakan dalam analisis kriteria pada pelaksanaan proyek konstruksi yang disarankan dapat dikembangkan dalam proyek kontruksi lainnya. Seperti Kontruksi gedung, rumah, jembatan, hingga bangunan air.

2. Metode yang digunakan dapat dikembangkan dengan metode Logika Fuzzy lainnya. Seperti Logika Fuzzy Mamdani, dan Logika Fuzzy Tsukamoto, sehingga mungkin dapat diperoleh hasil yang lebih optimal lagi.

3. Dapat mengembangkan Logika Fuzzy Interface System Takagi-Sugeno untuk masukan data yang lebih rinci lagi. Karena tiap proyek punya kebutuhan yang berbeda untuk menajadi masukan data dalam program menggunakan Logika Fuzzy FIS Takagi-Sugeno.

\section{DAFTAR PUSTAKA}

[1] C. Chen, G.W. Flintsch, dan I.L. Al-Qadi. 2004. Fuzzy Logic Based Life Cycle Cost Analysis Model for Pavement and Asset Management. Virginia, United States of America.

[2] Jamshid. S. 2005. Cost Estimation of Highway Projects in Developing Countries: Artificial Neural Network Approach

[3] Kusuma Dewi, S. et al. 2006. Fuzzy- Attribute Decision Making (FUZZY MADM). Graha Ilmu. Yogyakarta. 